Plum Publications of Santa Cruz, CA, hubiera estado bien incluir la dirección en Taiwan en un apéndice para aquellos lectores a los que les gustaría contactar con el Sr. Liu directamente.

La segunda mitad del libro se dedica a autores específicos y a los manuales que elaboraron, y cubre un intervalo de años desde 1500 hasta los tiempos modernos. Se incluyen sobre 33 autores, muchos de ellos con varias obras. Se ofrece para cada autor alguna historia de vida, incluyendo sus credenciales marciales así como información relativa a las historia de la publicación de sus libros. Esto demuestra que la obra es un gran regalo para aquellos de nosotros que hemos coleccionado estos manuales a lo largo de los años pero que no conocíamos mucho de los hombres que los escribieron. Algunos de los nombres serán familiares para los lectores con experiencias en las artes chinas, pero otros -algunos de los cuales eran grandes nombres en su época- serán menos conocidos. Sobre todo, estos ensayos proporcionan una excelente introducción a un amplio abanico de manuales de una variada selección de autores.

Kennedy y Guo han hecho un gran favor a la comunidad de artes marciales elaborando este libro. Han escrito un libro que será realmente útil tanto a principiantes como a practicantes avanzados. Su sensata aproximación no sentará bien a aquellos que quieren creer gran parte de la versión de la historia de las artes marciales chinas que presentan los Chop Socky [películas de peleas de kung-fu] o Kwai Chan Caine [el protagonista de la famosa serie televisiva Kung Fu, encarnado por David Carradine], y algunos practicantes más serios pueden discutir sobre ciertos aspectos, pero, sobre todo, para aquellos que quieren una visión acertada del desarrollo de las artes marciales desde una perspectiva histórica, este es ciertamente un libro muy valioso.

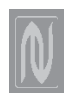

\section{Progressive Aikido: The Essential Elements}

Por Moriteru Ueshiba

Traducido por John Stevens

Tokyo: Kodansha International, 2005

195 páginas 20,3×25,4 cm.

Ilustraciones.

I.S.B.N.: 47-7002-172-0 $\$ 35.00$

Idioma: Inglés

Disponible en:

North Atlantic Books/Frog, Ltd.

P.O. Box 12327

Berkeley, CA 94712

Telf.: +1 800.337.2665

Fax: +1 510.559.8279

Email:

orders@northatlanticbooks.com

www.northatlanticbooks.com

Revisión por Guillermo Paz-y-Miño C. y Avelina Espinosa

Ueshiba nos ofrece en esta obra una aproximación enciclopédica y generosa al aikido tradicional. El libro es una guía gráfica y progresiva a las artes básicas del aiki donde el aikido es descrito como un arte marcial, un método de entrenamiento para el desarrollo mental y corporal, una táctica de autodefensa para la vida cotidiana, un reto físico y mental para el autoperfeccionamiento y como una alternativa de educación a largo plazo. El autor pone los ojos en el espíritu del lector esperando realizar primero una comunicación sobre filosofía y luego sobre aspectos físicos. La unificación de la intención mental con la acción física es el objetivo de las enseñanzas que se discuten en este útil volumen.

En último término el aikido es la armonización del $k i$, según señala el autor. "Ki es la energía vital del universo y la sutil función del ki anima los cinco sentidos. Emplea esa fuerza, con la unidad del cuerpo y la mente, y te podrás mover libre como desees", escribe Ueshiba. Y continúa aconsejándonos que evitemos los conflictos, comprendamos los patrones del movimiento y aceptemos las técnicas honrando la sofisticación del arte. Esto no debe ser confundido con poderes irreales de imposible existencia, sino como un lógico resultado final de la proyección de la anatomía humana en un mundo material y dinámico.

Sin embargo, si uno quiere tener este libro como compañero de aprendizaje es crucial capturar la verdadera intención del autor cuando lo compiló.

Ueshiba nos anima a "adquirir" el aikido estudiándolo con paciencia. Camina con el lector paso a paso, como dándole seguridad en su camino hacia el progreso y, optimistamente, hacia la perfección. El libro de Ueshiba nos hace sentirnos seguros, guiados y optimistas sobre nuestro futuro como practicantes del arte.

El libro es progresivo no sólo en su formato, que incluye mensajes crecientemente complejos tanto en el texto como en las fotografías, sino también en su contenido teórico que culmina en una apabullante exposición de la versatilidad de aikido. Si nuestra decisión es seguir este libro con disciplina, nos estaremos comprometiendo a años de entrenamiento antes de ser capaces de seguir con otro libro.

Se presentan con un detalle exquisito técnicas desde la posición de pie, formas de rodar, caídas, formas de caminar y técnicas de seguir o dirigir. Enriquecen el texto cientos de fotografías que son primeros planos, las cuales son normalmente precisas y suficientes como para comunicar tanto las rutinas básicas como avanzadas. El autor enfatiza las técnicas de muñeca, los ataques con la mano abierta, algunos agarres, inmovilizaciones y algunas proyecciones con dos atacantes. Se dedica una sección completa al tanto o cuchillo, particularmente a inmovilizaciones. El libro finaliza con la etiqueta y algunos métodos adicionales de entrenamiento, incluyendo saludos, forma de estar de pie y sentarse, ejercicios y estiramientos de calentamiento [o vuelta a la calma], habitualmente ubicados al principio de la mayoría de los libros. La intención es elocuente: el aikido comienza y finaliza con la calma. Es muy fácil olvidar que en este arte la pausa es la necesaria antítesis del movimiento, y que un exacto equilibrio entre pausa y el movimiento es lo que define al aikido.

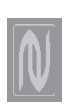

